\title{
CHILDREN SHOULD BE TREATED WITH RESPECT AND DIGNITY
}

Newly published guidance ${ }^{1}$ to improve how children and young people (CYP) experience healthcare is welcomed by the British Society of Paediatric Dentistry (BSPD). Drafted by NICE (the National Institute for Health and Care Excellence), the guidance is designed to ensure the preferences and feelings of young patients are consistently central to their treatment.

This approach is already espoused by BSPD whose members have researched and published systematic reviews ${ }^{2}$ highlighting the importance of making the voice of the child central to research and put children and young people in control of their dental treatment. $^{3}$

The NICE guidance covers issues such as safeguarding, disabilities, consent, shared decision-making and sets out that healthcare staff should communicate with:

- Kindness, compassion and respect

- Cultural sensitivity

- A non-judgemental attitude.

It is aimed at commissioners and providers of healthcare who now have a responsibility to apply the guidance where appropriate. It should also be read by nonclinical staff, such as receptionists.

Professor Paul Ashley, a member of BSPD as well as the NICE committee who drafted the guidance, said: 'Children have a right to express their views on decisions affecting them. This guidance shows how listening to and treating children and young people with the respect and dignity they deserve can lead to better care.

'Poor healthcare experiences increase likelihood of unmet healthcare need among CYP, which could mean worse health outcomes in adult life. Positive experiences of healthcare also play an important part in health equality, ensuring that every contact counts to build up trust.'

He added: 'Paediatric dentists are already adept at tuning in to their patients' needs and wishes. This has become more challenging since the pandemic with remote check-ins replacing face-to-face care. Familiarity with dental clinics is fundamental to allow children and young people to develop confidence and trust in our services'.

\section{References}

1. NICE. Babies, children and young people's experience of childcare. NICE guideline NG204. 25 August 2021. Available at: https://www.nice.org.uk/ guidance/ng204 (accessed 31 August 2021).

2. Marshman Z, Gibson B J, Owens J et al. Seen but not heard: a systematic review of the place of the child in 21st-century dental research. Int J Paediatr Dent 2007; 17: 320-327.

3. The University of Sheffield. Help! I'm scared of the dentist. Available at: https://www.sheffield.ac.uk/research/ features/help-im-scared-dentist (accessed 31 August 2021).

\section{BADN SUPPORTS SAFE SMILES CAMPAIGN}

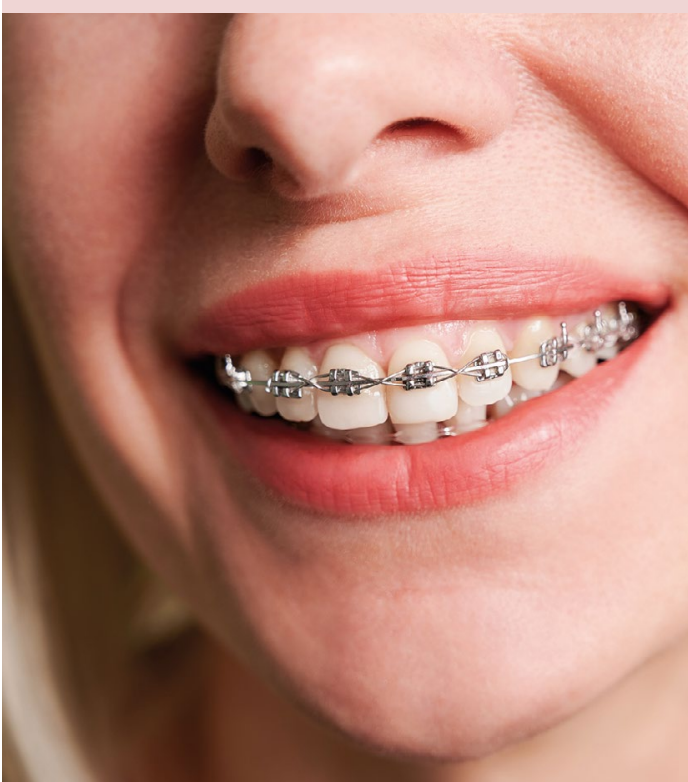

The British Association of Dental Nurses (BADN) is delighted to be part of the Oral Health Foundation's Safe Smiles campaign, launched in September at the British Orthodontic Conference in Manchester. The campaign will give advice and support on how to get a great smile in a safe way, and will stress the importance of having dental treatment in dental practices, carried out by registered professionals.

The Safe Smiles campaign is in response to the growth of direct-toconsumer alternatives and will also address dental tourism, inappropriately fitting mouthguards, harmful aesthetics such as lip tattoos, oral piercings and tooth jewellery, and the dangers these present; and will urge the public to only have treatment carried out by General Dental Council (GDC) registered dental professionals in dental practices in the UK.

The Safe Smiles campaign has been endorsed by the leading dental professional associations - the British Dental Industry Association (BDIA), the British Academy of Cosmetic Dentistry (BACD), the British Society of Dental Hygiene and Therapy (BSDHT) and the British Association of Dental Therapists (BADT), as well as by BADN.

BADN President Jacqui Elsden said 'We shall be working closely with the Oral Health Foundation to encourage dental nurses to become involved with the campaign - information on how to do this will be on our website www.badn.org.uk'. 